\title{
Effect of board game and quick draw total participation techniques on students' scientific inquiry skill
}

\author{
Averilla, Rommel $\square$ \\ Emilio Aguinaldo College, Philippines (rommelaverilla.mnl@eac.edu.ph)
}

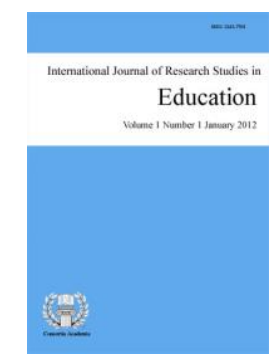

Accepted: 30 May 2021 Online ISSN: 2243-771

OPEN ACCESS

\section{Abstract}

The study was conducted to investigate the effectiveness of Board Game and Quick Draw Total Participation Techniques on Students' Scientific Inquiry Skill. Furthermore, it was conducted to find out other methods of instruction that can be used in teaching science focusing on the 21st-century skills of the students namely, predicting, investigating, and interpreting. The study wants to look at the alternative way on how to develop and improve the scientific inquiry skills of the students without consuming a lot of time and at the same time efficient on its purpose. It aimed to determine the difference in the pretest and posttest scores, and correlate the students' level of scientific inquiry skills on different teaching strategies. A pretest-posttest design of quasi-experimental research was used. One hundred thirty-two Grade 7 students from Basic Education Curriculum clustered into three groups were selected as respondents in Pedro Guevara Memorial National High School. Pretest-posttest questionnaire questions were utilized to obtain the data. Results revealed that the gain scores varied according to the techniques, skills, and techniques-skills interaction. The three different teaching techniques have different effectiveness in teaching science. There is also a difference in results on students' scientific inquiry skills namely predicting, investigating, and interpreting based on the analysis of variance. On the other hand, there is also a significant interaction between techniques and skills. Different techniques show different effects on different scientific inquiry skills. The result shows that quick draw is the best technique to develop predicting and investigating skills, while the board game is the best technique to use in developing interpreting skills.

Keywords: total participation techniques; scientific inquiry skill; predicting skills; developing skills; interpreting skills 


\section{Effect of board game and quick draw total participation techniques on students' scientific inquiry skill}

\section{Introduction}

The $\mathrm{K}$ to 12 Enhanced Basic Education Curriculum's main feature is the development of learners to become productive members of the society, equipping them with the essential competencies, skills, and values for both lifelong learning and employment (Luistro, 2012). Accordingly, the K to 12 science education aims to develop scientific literacy among learners that will equip them to be knowledgeable and active citizens. The curriculum is designed to develop among the students the understanding and applying scientific knowledge in the local setting and global context whenever possible, performing scientific processes and skills, and developing and demonstrating scientific attitudes and values (K to 12 Science Curriculum Guide, 2016).

The core of science education is allowing students to make progress and productive roles in acquiring learning through their discovery and exploratory processes. Notably, it helps students to construct and organize their ideas, reflect on problems, look for evidences, and formulate a hypothesis. These processes can help them concretize their thinking skills and nurture their problem-solving abilities, thus facilitating the learning of scientific concepts (SEI-DOST and UP NISMED, 2011). Scientific cognition and skills are essentials in science and given much time in discussion inside the classroom. $\mathrm{K}$ to 12 educators are trained to teach these fundamentals as dictated by the standardized evaluations to meet the competencies mandated by the curriculum. Thus, many students are leaving the $\mathrm{K}$ to 12 education system lacking critical thinking skills that are essential to succeed in higher education or the workplace (Smith \& Szymanski, 2013).

Scientific inquiry skills are considered a major intellectual and practical skill in science education. This supports the major understanding of the learners toward the environment and society. But these skills lack not only function but also in understanding what the concept is. It requires not just learning effort but maximum exertion of intellectual capability and personal reflection (Rowles et al., 2013). Science education involves practical and major intellectual skills in developing critical thinking. This helps students understand their environment and community. Unfortunately, this skill lacks an understanding of what the concept is. It requires personal reflection and maximum effort on intellectual capability (Choy \& Cheah, 2009).

To secure the proper implementation of the curriculum, the Department of Education Region IV-A CALABARZON released the enclosed instructional guide called "The 2C-2I-1R: K to 12 Approaches Across Learning Areas that Support Teacher Practice" for use by all the curriculum implementers (San Antonio, 2015). This is in line with the goals of the Republic Act No. 10533 (Enhanced Basic Education Act of 2013), Section 5 which states that the curriculum that must be reflected in the teaching and learning process should be relevant, responsive, and research-based. The teachers as the curriculum implementers are encouraged to use the five pedagogical approaches called 2C-2I-1R, namely: Constructivist, Collaborative, Inquiry-based, Integrative and Reflective in facilitating learner-centered instruction, in establishing teaching and learning process, and in making relevant curriculum and (DepEd Regional Memorandum No. 11 s. 2015, 2015). Thus, providing techniques that would address the need for developing and empowering the necessary skills among learners in the 21st-century setting is a need. Scientific undertaking where students will be able to acquire information through self-constructed investigations and activities while conducting social learning interaction among others should be implemented. The $\mathrm{K}$ to 12 Curriculum asserts the use of collaborative approaches to developing students' scientific inquiry skills. (Colley, 2008).

This leads the researcher to investigate the use of board games and quick draw total participation techniques in assessing students' scientific inquiry skills. It aims to seek if these strategies will be an effective tool to teach the students in developing scientific inquiry skills needed in studying science. 


\subsection{Objectives of the Study}

This study aimed to investigate the effect of the board games and quick draw total participation techniques on students' scientific inquiry skills among Grade 7 students of Pedro Guevara Memorial National High School. Specifically, it sought to answer the following questions:

$>$ What is the mean pre-test score of students before exposure to the board game, quick draw total participation techniques, and the activity techniques in terms of predicting, investigating, and interpreting?

$>$ What is the mean post-test score of students exposed to exposure to board games and quick draw total participation techniques and the activity techniques in terms of predicting, investigating, and interpreting?

$>$ What is the mean gain score of the students in terms of the following scientific inquiry skills in terms of predicting, investigating, and interpreting?

$>$ Is there a significant difference in the mean pre-test and post-test scores of students in terms of predicting, investigating, and interpreting?

$>$ Is there a significant difference between the mean gain scores of students exposed to board game and quick draw total participation techniques and the activity techniques as to their scientific inquiry skills in predicting, investigating, and interpreting?

\section{Methodology}

Describe the research method used in the study. Sampling technique, respondents/participants of the study, setting, research instrument, validation, reliability testing, data analysis (quantitative or qualitative), ethical considerations. This study used the pretest-posttest design of quasi-experimental research which is the blueprint of the procedure that enables the researcher to test his hypothesis by reaching valid conclusions about the relationship between independent and dependent variables. This study attempts to accumulate existing information and data gathering on the use of board games, quick draw total participation techniques, and activity techniques. Improving students' scientific inquiry skills that were based on the three-group design in which there are three selected groups under observation, with a careful measurement being done before applying the experimental treatment and then measuring after. This study depicted the current state of instruction of lessons inside the classroom during science class. The result was collected through the implementation of pre-test and post-test before and after the lesson to see the difference of the result whether the use of board games, quick draw total participation techniques, and the activity techniques are effective in the development of students' scientific inquiry skills.

Grade 7 students of Pedro Guevara Memorial National High School served as samples of this study. The heterogeneous sections used in the study were composed of three groups. Each group was exposed to different teaching strategies and the result of their pre-test was compared against their post-test that was given before/after the implementation of the study. Three selected sections as samples for the study were composed of 44 per section for a total of 132 Grade 7 students. The board game, quick draw total participation techniques and activity techniques were used among the 132 Grade 7 students that took the pre-test and post-test. The study used pre-test and post-test as a tool that measured the students' achievement on the use of board games, quick draw total participation techniques, and the activity techniques in teaching physics and the development of grade 7 scientific inquiry skills such as predicting, investigating, and interpreting.

The test questionnaire was composed of 20 questions per module prescribed by the Department of Education that were used for pre-test and post-test that will cover the topics that cover topics from motion, waves, and sound. The questions covered the skills needed to develop such as predicting, investigating, and interpreting that fall 
under the scientific inquiry skills of the students. The responses on the questionnaires were tabulated to see how the students fair on the use of the board game, quick draw total participation techniques, and the activity techniques in teaching physics shown in the result of pre-test and post-test. Using validity and reliability indices will guarantee the accuracy of the desired result of the study.

The collection of data begins when the research instrument is approved by the panel. Before the implementation of the study, the test questions undergo validity among experts in the fields such as master teachers and head teacher, respectively. The questionnaire was distributed to solicit the views and opinions of experts regarding the pre-test/post-test that was used. The result of validity was consolidated to see how the experts perceived the test questions before it is used in the actual classroom instruction. In connection with this, validation of the board game and quick draw total participation techniques was undertaken to find out whether the proposed tool suits the nature, needs, and levels of the students. Expert judgment in the fields such as Head Teacher and Master Teachers was asked by the researcher to validate the content present in the board game and quick draw total participation techniques. This is to ensure that the proposed materials are aligned with the expected competencies for the topics under study.

Afterward, upon the approval of the principal of Pedro Guevara Memorial National High School, the researcher asked permission from the head teacher to use three selected heterogeneous sections as samples for the study. The chosen respondents undergo pre-test and post-test before and after the implementation of the board game, quick draw total participation techniques activity techniques in the instruction of lessons in the classroom. Group 1 used the board game, group 2 used the quick draw, and group 3 used the activity techniques. It takes twenty days to complete the three modules as suggested time allotment by the Department of Education. The test result was collected and compared to see if the implementation approach in teaching science is effective or not. The result undergoes statistical treatment to see if there is a significant change that will happen after the implementation of the board game, quick draw total participation techniques activity techniques.

Since the study is mainly experimental, the researcher will employ statistical testing for hypotheses. This study used the t-test to test the difference, mean, mean gain, mean difference, and analysis of variance (ANOVA) in the performance of grade 7 students. This shows how the board game, quick draw total participation techniques, and the activity techniques may affect the students' scientific inquiry skills and how it may help them perform better in the classroom. Data were presented in tables to show if there is a change in the students' inquiry skills with the use of board games, quick draw total participation techniques activity techniques.

\section{Results and Discussion}

\section{Table 1}

Pre-test of students before exposure to the board game, quick draw total participation techniques, and activity

\begin{tabular}{lcccc}
\hline \multicolumn{1}{c}{ Group } & Predicting & Investigating & Interpreting & Overall Mean per Group \\
\hline 1 & 6.614 & 6.364 & 5.796 & 6.258 \\
2 & 6.296 & 6.296 & 6.432 & 6.341 \\
3 & 6.523 & 6.522 & 5.750 & 6.265 \\
Overall Mean (Skills) & 6.478 & 6.394 & 5.993 & 6.288 \\
\hline
\end{tabular}

Legend: 0-4: Beginning; 5-9: Developing; 10-14: Proficient; 15-20: Highly Proficient.

Table 1 shows the summary of mean pre-test scores of students before exposure to the board game, quick draw total participation techniques, and the activity techniques the three groups of students take the same pre-test questions before exposure to the board game, quick draw total participation techniques, and the activity techniques. Based on the table above, students under Group1 are more into predicting skills while students under Group 2 are more into interpreting skills and lastly, students under Group 3 are more into both predicting and investigating skills. Students' overall mean in terms of skills shows that they are mostly at the developing stage by the verbal interpretation of each means in each skill. It shows that students' scientific inquiry skill needs 
Effect of board game and quick draw total participation techniques on students' scientific inquiry skill

improvement although they have prior knowledge in the subject. Based on the group's overall mean indicates that each group is still under the developing stage before exposure to teaching techniques.

A study conducted by Rodrigo et al. (2011) pointed out that prior knowledge has a strong influence on the pre-test performance of students thus it can be contributed to the mean score result of the test and can be cited to support the mean pre-test score of the students. Ely (2015) supported the study that pre-test must be administered to determine students' baseline knowledge or preparedness for an educational experience or course of study. This must be done to assess the normality of students in acquiring creative thoughts by their effort by making progress as a result of their own and others' responses to stimuli of questioning and volunteered expression during the class discussion.

Table 2

Post-test of students after being exposed to board game, quick draw total participation techniques, and activity

\begin{tabular}{lcccc}
\hline \multicolumn{1}{c}{ Group } & Predicting & Investigating & Interpreting & Overall Mean per Group \\
\hline Board Game & 11.89 & 11.11 & 10.05 & 11.01 \\
Quick Draw & 12.30 & 11.89 & 10.25 & 11.48 \\
Activity Techniques & 10.77 & 9.84 & 9.64 & 10.08 \\
Overall Mean (Skills) & 11.65 & 10.95 & 9.98 & 10.90 \\
\hline
\end{tabular}

Legend: 0-4: Beginning; 5-9: Developing; 10-14: Proficient; 15-20: Highly Proficient.

Table 2 shows the summary of the mean post-test score of students after being exposed to the board game, quick draw total participation techniques, and the activity techniques. Based on the above table, students who use the board game from Group 1 achieved the highest mean post-test score in predicting skill followed by investigating skill and lastly the interpreting skill. Students' who use the quick draw under group 2 achieved the highest mean post-test score in predicting skill followed by investigating skill and interpreting skill. Under the activity techniques, predicting skill got the highest mean post-test score among the scientific inquiry skills followed by investigating skill then the interpreting skill. In terms of the overall mean score per group, each group achieved a proficient level. Group 2 uses the quick draw has the highest mean post-test score, followed by Group 1 with the board game, and lastly, group 3 uses the activity techniques. On the other hand, the overall mean post-test score per skill shows that predicting skill gain the highest mean post-test score followed by investigating and lastly, interpreting skill. Based on the result, it can be said that all teaching techniques are an effective tool in developing students' scientific inquiry skills.

As cited by Stabler (2014), a post-test is the most viable measure to determine the outcome after the laboratory method has been deployed in learning science. Similar to a study conducted by Resurreccion (2014) entitled the effects of using video on teaching selected topics in physics towards the development of higher-order thinking skills, it proves that students performed better as provided by the mean post-test result. The study shows how the mean post-test result has improved after the implementation of the study, just like what this study has achieved after the board game, quick draw total participation techniques and the activity techniques was used in improving the scientific inquiry skills of the students as what the mean post-test result has shown.

Table 3

Summary of the test of difference on the mean pre-test and post-test of students' scientific inquiry skills.

\begin{tabular}{lcccccc}
\hline \multirow{2}{*}{ Group } & \multicolumn{2}{c}{ Predicting } & \multicolumn{2}{c}{ Investigating } & \multicolumn{2}{c}{ Interpreting } \\
& Df & VI & Df & VI & Df & VI \\
\hline Board Game & 5.27 & HS & 4.75 & HS & 4.25 & HS \\
Quick Draw & 6.00 & HS & 5.59 & HS & 3.82 & HS \\
Activity Techniques & 4.25 & HS & 3.32 & HS & 3.89 & HS \\
\hline
\end{tabular}

Table 3 shows a summary of the mean difference score of students and their scientific inquiry skills. Group 1 who uses the board game shows a positive result on developing students' scientific inquiry skills. The board game has brought a highly significant difference to students' scientific inquiry skills indicating that it is an 
Averilla, R.

effective technique to use. Group 2 who uses the quick draw also shows a positive result showing a highly significant difference. Group 3 who uses the activity techniques also shows a positive result in developing students' scientific inquiry skills with a highly significant difference. Table 3 also shows what teaching technique is most effective in improving inquiry skills. Among the groups, Group 1 who use the board game It can also be noted that predicting skill benefited the most in the teaching techniques as it shows great improvement, most specifically the quick draw has a great impact on the skill receiving the highest mean difference. The result of the study supports the findings of Marasigan (2006) in his study entitled "The use of games in teaching selected topics in Chemistry" said that the use of educational games is an effective adjunct to the traditional method of teaching based on mean difference result of pretest and posttest.

Another study proved the effectiveness of various teaching strategies, as stated by Tabago (2014) that a significant difference between pre- and post-achievement scores of the students and positive feedback towards physics were also drawn from them. These results implied that the use of a collaborative inquiry classroom approach helped the students enhanced their thinking skills. In a study, King et al. (2005) underscored that thinking skills which may also include critical, logical, analytical, reflective, and metacognitive are activated when students deal with problems, uncertainties, and questions. This will result to enrich their explanations, decisions, and performances.

\section{Table 4}

Comparison of skills after exposure to board game

\begin{tabular}{lccc}
\hline \multicolumn{1}{c}{ Scientific Inquiry Skills } & $\mathrm{n}$ & Mean & SD \\
\hline Predicting & 44 & $5.273 a$ & 2.653 \\
Investigating & 44 & $4.750 a$ & 2.642 \\
Interpreting & 44 & $4.250 a b$ & 2.754 \\
\hline Legend: Means with the same letter are not significantly different. & &
\end{tabular}

Legend: Means with the same letter are not significantly different.

Table 4 presents the comparison of scientific inquiry skills with the use of Board Game. Using the board game predicting skill has a mean value of 5.273 and a standard deviation of 2.653, investigating skill has a mean value of 4.750 and a standard deviation of 2.642 and for interpreting skill, it has a mean value of 4.250 and a standard deviation of 2.754. Using the board game, the table shows that among the scientific inquiry skills, more students develop predicting skills followed by investigating then interpreting skills. Predicting skill and investigating skill shows not significantly different and with a significant difference in interpreting skill.

\section{Table 5}

Comparison of skills after exposure to quick draw

\begin{tabular}{lccc}
\hline Scientific Inquiry Skills & $\mathrm{n}$ & Mean & SD \\
\hline Predicting & 44 & $6.000 a$ & 2.787 \\
Investigating & 44 & $5.591 a$ & 3.045 \\
Interpreting & 44 & $3.818 b$ & 2.116 \\
\hline
\end{tabular}

Legend: Means with the same letter are not significantly different.

A comparison of scientific inquiry skills with the use of Quick Draw is shown in table 5. Predicting skill has a mean score of 6.000, investigating skill got a mean score of 5.591 and for interpreting skill, it has a mean score of 3.818. Students' mean score shows that they mostly develop predicting skills in using quick draw followed by investigating skill and lastly, interpreting skill. Predicting skill and investigating skill shows not significantly different and with a significant difference in interpreting skill.

Table 6

Comparison of skills after exposure to activity techniques.

\begin{tabular}{lccc}
\hline \multicolumn{1}{c}{ Scientific Inquiry Skills } & $\mathrm{n}$ & Mean & SD \\
\hline Predicting & 44 & $4.250 a b$ & 2.535 \\
Investigating & 44 & $3.318 b$ & 2.639 \\
Interpreting & 44 & $3.886 a b$ & 2.581 \\
\hline Legend: Means with the same letter are not significantly different. & &
\end{tabular}

Legend: Means with the same letter are not significantly different. 
The above table shows the comparison of scientific inquiry skills with the use of activity techniques. Predicting skill has the highest mean score of 4.250, investigating skill has a mean score of 3.318 and for interpreting skill, it has a mean score of 3.886. Students' mean score shows that they mostly develop predicting skills in using activity techniques followed by interpreting skills and lastly, investigating skills. Predicting skills and interpreting skills shows not significantly different and with a significant difference in investigating skills.

\section{Conclusion and recommendation}

Total Participation Techniques such as game board and quick draw improved the students' scientific inquiry skills such as predicting, investigating, and interpreting. Furthermore, based on the findings, the following conclusions were hereby drawn:

$>\quad$ The three techniques used by the researcher, namely board game, quick draw, and activity technique, show that there was a significant increase from the pretest result to the posttest result of the students.

$>\quad$ The students' scientific inquiry skills namely predicting, investigating, and interpreting show a significant increase from the pretest results to the posttest result.

$>\quad$ The gain scores varied according to the techniques, skills, and techniques-skills interaction. The three different teaching techniques have different effectiveness in teaching science. There is also a difference in results on students' scientific inquiry skills namely predicting, investigating, and interpreting based on the analysis of variance.

$>\quad$ There is a significant interaction between techniques and skills. Different techniques show different effects on different scientific inquiry skills. The result shows that quick draw is the best technique to develop predicting and investigating skills, while the board game is the best technique to use in developing interpreting skills.

Considering the findings and conclusions in the study, the following recommendation is advised:

$>$ The teachers need to use various teaching strategies preferably the total participation techniques as an alternative and innovative method to improve the achievements of students. The teachers need to streamline the learning environment that can equalize interaction and accommodate experiential learning with students enabling greater learner participation, satisfaction, and further academic motivation.

$>\quad$ Teachers are encouraged to be more innovative and creative in using total participation techniques. Due to the positive effects of the teaching techniques namely board game and quick draw in the students' scientific inquiry skills.

$>\quad$ The teachers, principals, parents, and supervisors are encouraged to provide help and support on the use of the approach for the improvement of students' scientific inquiry skills leading them to improve class performance. Facilities should be made available for the utilization of students; support of parents is highly needed as it might serve as one of the motivations of students inside the classroom.

$>\quad$ Science supervisors should identify this as an effective learning method that would be suitable to provide favorable learning conditions for all the students rather than just using the common approach in teaching.

\section{References}

Choy, C., \& Cheah, P. K. (2009). Teacher perceptions of critical thinking among students and its influence on higher education. International Journal of Teaching and Learning in Higher Education, 20(2), 198-206. 
Averilla, R.

Colley, K. (2008). Project-based science instruction: A primer. The Science Teacher, 75(3), 23-27.

DepEd Regional Memorandum No. 11 s. 2015. (2015). The 2C-2I-1R Approaches. Cainta, Rizal: Department of Education Region IV-A CALABARZON.

DepEd Regional Memorandum No. 233 s. 2016. (2016). Implementation of the pedagogical approaches mandated by R.A. 10533. Cainta, Rizal: Department of Education region IV-A CALABARZON.

Ely, D. (1983). Development and use of the ARCS model of motivational design. Classic Writings on Instructional Technology. Libraries Unlimited.

King, F., Goodson, L., \& Rohani, F. (2005). Higher order thinking skills. Center for Advancement of Learning and Assessment.

Lozada, M. V. B. (2012). The effect of metacognitive learning strategy in physics achievement (Master's Thesis). Mambusao: Capiz State University.

Luistro, A. (2012). Central feature of the K to 12 basic education curriculum. Pasig City: Department of Education.

Marasigan, E. (2006). The use of games in teaching selected topics in chemistry (Master's Thesis). Manila: Technological University of the Philippines.

Resurreccion, R. D. (2004). The effects of using videos on teaching selected topics in physics towards the development of higher-order-thinking skills. (Master's Thesis). Cavite: Cavite State University - Silang Campus.

Rodrigo, M., et.al. (2011). Impact of prior knowledge and teaching strategies on learning by teaching (Master's Thesis). Quezon City: Ateneo de Manila University.

Rowles, J., Morgan, C., Burns, S., \& Merchant, C. (2013). Faculty perceptions of critical thinking at the earth sciences university. Journal of the Scholarship of Teaching and Learning, 13(4), 21-35.

SEI-DOST and UP NISMED. (2011). Science framework for Philippine Basic Education. Manila: SEI-DOST and UP NISMED.

Smith, V., \& Szymanski, A. (2013). Critical thinking: More than test scores. International Journal of Educational Leadership Preparation, 8(2), 16-26.

Stabler, E. (2014). Posttest in teaching science. North Carolina: Educational Pamphlet Bimonthly.

Tabago, L. C. (2014). Pinoy game-based activities in teaching concepts of work, power and energy. IAMURE International Journal of Multidisciplinary Research, 8(1). https://doi.org/10.7718/iamure.v8i1.788 